\title{
The Relationship between Executive Outpatient and Human Rights Protection for BPJS Health Patients in RSUD KRMT Wongsonegoro Semarang
}

\author{
Hubungan Penyelenggaraan Rawat Jalan Eksekutif Dengan Perlindungan HAM Pasien BPJS \\ Kesehatan Di RSUD KRMT Wongsonegoro Semarang \\ I Wayan Agus Setiawan, Budi Sarwo, Daniel Budi Wibowo \\ email: agussetiawan557@gamail.com
}

Health Law Master Program, Soegijapranata Catholic University of Semarang

\begin{abstract}
Health was very important to human beings and was protected by the state because to get health was part of human rights, and it should be protected by the state. Health warranty was one of the protection forms provided by the government so that the rights to obtain health could be fulfilled. KRMT Wongsonegoro Hospital was a hospital that provided services to the patients of BPJS and organized executive and regular outpatients. The existence of two kinds of outpatients led to a necessity of seeing the protection to the patients getting social security in obtaining executive outpatient services.

This research used a socio-legal approach having an analytical-descriptive specification. It would describe the implementation of the executive outpatient services and be then analyzed to see the relationship between the rights of the patients of Health BPJS and human rights protection.

The results of the research showed that KRMT WongsonegoroHospital issued a Director's Decree Nr. 290 of 2017 on Opening of Executive Outpatient of Gatotkaca and a Director's Regulation Nr. 50 of 2017 on Executive Patient Cost Package. KRMT Wongsonegoro Hospital had not been able to thoroughly schedule specialist and subspecialist doctors for executive outpatients. For the time being KRMT Wongsonegoro Hospital did not take any additional cost for executive outpatient services.
\end{abstract}

Keywords: executive outpatient, human rights protection to patients of Health BPJS

\section{PENDAHULUAN}

Kesehatan merupakan hal yang sangat penting bagi manusia dan sangat dibutuhkan oleh manusia. Kesehatan merupakan bagian yang penting untuk kesejahteraan masyarakat di suatu negara. Pentingnya kesehatan untuk kesejahteraan masyarakat maka, untuk memperoleh pelayanan kesehatan negara harus bisa menjamin masyarakat untuk mendapatkan pelayanan yang mudah dan tidak adanya diskriminasi dalam pemberian pelayanan kesehatan. 
Sistem jaminan sosial nasional merupakan suatu jaminan untuk memenuhi jaminan kebutuhan dasar manusia yang layak. Sistem jaminan sosial nasional pada dasarnya merupakan program negara yang bertujuan memberi kepastian perlindungan dan kesejahteraan sosial bagi seluruh rakyat Indonesia. Melalui program ini, setiap penduduk diharakan dapat memenuhi kebutuhan dasar hidup yang layak apabila tejadi hal-hal yang dapat mengakibatkan hilang atau berkurangnya pendapatan, karena menderita sakit, mengalami kecelakaan, kehilangan pekerjaan, memasuki usia lanjut, atau pensiun.

Rumah sakit adalah unit pelayanan kesehatan terhadap masyarakat baik individu atau keluarga yang membutuhkan pelayanan kesehatan baik dari segi prepentif, kuratif, rehabilitatif, maupun promotif yang dilaksankan secara terpadu dalam pelayanan kesehatan. Rumah sakit mempunyai peran yang sangat penting dalam memenuhi hak kesehatan untuk masyarakat.

Pada tahun 2016 pemerintah menetapkan pelayanan rawat jalan eksekutif bagi masyarakat yang diatur dalam Peraturan Menteri Kesehatan Nomor 11 Tahun 2016 tentang Penyelenggaraan Rawat Jalan Eksekutif Di Rumah Sakit, dapat diartikan sebagai pemberian pelayanan kesehatan rawat jalan non reguler di rumah sakit yang diselenggarakan melalui pelayanan dokter spesialis-subspesialis dalam satu fasilitas ruangan terpadu secara khusus tanpa menginap di rumah sakit dengan sarana dan prasarana di atas standar.

RSUD KRMT Wongsonegoro Semarang merupakan rumah sakit yang sudah melayani pasien rawat jalan reguler dan pasien rawat jalan eksekutif. Adanya rawat jalan eksekutif dan rawat jalan reguler dalam satu rumah sakit maka peneliti tertarik mengambil penelitian tentang "Hubungan Penyelenggaraan Rawat Jalan eksekutif dengan Perlindungan HAM Pasien BPJS Kesehatan di RSUD KRMT Wongsonegoro Semarang."

\section{PERUMUSAN MASALAH}

Adanya rawat jalan eksekutif dalam satu rumah sakit dan disaat pemerintah sedang berusaha mengujudkan sistem jaminan sosial bagi seluruh rakyat Indonesia, sedangkan rawat jalan eksekutif merupakan rawat jalan yang dapat diakses oleh pasien umum dan BPJS Kesehatan maka akan menimbulkan pertanyaan: apakah pelayanan rawat jalan dapat mempermudah masayarakat dalam memperoleh pelayanan atau akan memunculkan pelayanan diskriminasi ?. Karena dalam UUD 1945 Pasal 28 dan 34 dijelaskan semua orang berhak atas kesehatan dan adanya suatu jaminan untuk memperoleh hak tersebut dari pemerintah. Adapun rumusan masalah dalam penelitia ini yang akan dikaji bagaimana pengaturan rawat jalan eksekutif, bagaimana pelayanan rawat jalan eksekutif dan bagai mana perlindungan HAM pasien BPJS Kesehatan dalam memperoleh rawat jalan eksekutif. 


\section{METODE PENELITIAN}

Dalam penelitian ini menggunakan metode pendekatan yuridis normatif, dimana data primer didapat lansung dari RSUD KRMT Wongsonegoro Semarang, sedangkan untuk spesifikasi yang digunakan deskriftif analitik. Sedangkan untuk desain yang digunakan dalam penelitian ini kualitatif. Penelitian ini menggunakan data primer dan data skunder, dimana data primer diperoleh lansung dari RSUD KRMT Wongsonegoro melalui wawancara, dan observasi.

Karena banyaknya populasi dalam penelitian ini maka peneliti menerapkan teksik sampel untuk dipilih jadi responden. Teknik sampel yang digunakan dalam penelitian ini purposive sampling.

\section{PEMBAHASAN}

\section{Pengaturan Penyelenggaraan Rawat Jalan Eksekutif di RSUD KRMT Wongsonegoro Semarang}

Rawat jalan eksekutif yang berada di RSUD KRMT Wongsonegoro Semarang, direktur menetapkan Keputusan Direktur Nomor 290 Tahun 2017 tentang Pembukaan Rawat Jalan Eksekutif Paviliun Gatotkaca Rumah Sakit Umum Daerah KRMT Wongsonegoro Semarang, sebagai tanda diresmikanya rawat jalan eksekutif. Selain keputusan di atas direktur juga mengeluarkan Keputusan Direktur Nomor 50 Tahun 2017 tentang Penetapan Tambah Biaya Paket Pelayanan Rawat Jalan Eksekutif yang dimana sebelumnya sudah diatur dalam Permenkes Nomor 11 Tahun 2016 tentang Penyelenggaraan Rawat Jalan Eksekutif di Rumah Sakit Pasal 14 yang berbunyi:

Pasal 14 ayat ( 1 )

“ Besaran tarif pelayanan rawat jalan eksekutif di rumah sakit ditetapkan oleh masing-masing kepala atau direktur rumah sakit sesuai dengan perhitungan pola tariff rumah sakit."

Pasal 14 ayat (2)

"Untuk peserta JKN besaran tarif pelayanan rawat jalan eksekutif sebagai mana dimaksud ayat (1) sesuai ketentuan peraturan perundang-undangan.

Persyaratan dasar yang harus dipenuhi rumah sakit dalam pelayanan rawat jalan eksekutif berupa ketentuan Permenkes Nomor 11 Tahun 2016 tentang Penyelenggaraan Rawat Jalan Eksekutif Pasal 2:

Ayat (1)

"Pelayanan rawat jalan eksekutif di rumah sakit hanya diselenggarakan pada rumah sakit kelas A, kelas B, dan Kelas C milik pemerintah pusat, pemerintah daerah dan masyarakat." 
Ayat (2)

"Rumah sakit sebagaimana dimaksud pada ayat (1) harus rumah sakit yang telah terakreditasi."

RSUD KRMT Wongsonegoro Semarang dalam Peraturan Walikota Semarang Nomor 14A Tahun 2017 tentang Peraturan Internal Rumah Sakit (Hospital By Law) RSUD KRMT Wongsonegoro Semarang Pasal 1 poin 6 dijelaskan bahwa RSUD KRMT Wongsonegoro Semarang merupakan rumah sakit kelas $B$ dan sudah mendapatkan akreditasi paripurna, sehingga RSUD KRMT Wongsonegoro sudah dapat membuka rawat jalan eksekutif.

Dalam pengorganisasian direktur mengeluarkan Keputusan Direktur Nomor 269 Tahun 2017 tentang Pengangkatan Manajer Paviliun Gatotkaca RSUD KRMT Wongsonegoro Semarang, yang dimana dalam Diktum Kesatu menjelaskan bahwa dr. Eko Krisnanto Sp.KK menjadi manajer paviliun Gatotkaca, dan mempunyai tugas:

“Manajer mempunyai tugas pokok membantu wakil direktur pelayanan dalam mengkoordinasikan kebutuhan dan tugas-tugas pelayanan medis, pelayanan perawatan, kegiatan administrasi dan logistic di paviliun Gatotkaca (rawat inap dan rawat jalan)."

Adanya keputusan direktur dalam peyalannan rawat jalan eksekutif sangat penting bagi rumah sakit karena direktur mempunyai tugas menyusun kebijakan dalam rumah sakit. Peraturan Walikota Semarang Nomor 14A Tahun 2017 tentang Peraturan Rumah Sakit (Hospital By Laws) Rumah Sakit Umum Daerah KRMT Wongsonegoro Kota Semarang Pasal 11 dijelaskan bahwa:

"Direktur sebagai mana dimaksud Pasal 10 huruf a, mempunyai tugas merencanakan, memimpin, mengkoordinasikan, menyusun kebijakan, mengarahkan, membina, mengawasi, mengendalikan, dan mengevaluasi pelaksanaan tugas dan fungsi sebagaimana dimaksud dalam Pasal 10 huruf $b$, huruf $c$, huruf $d$, huruf e, huruf $f$, huruf $g$, huruf h, dan huruf i."

Direktur dalam hal ini sebagai pimpinan tertinggi di rumah sakit mempunyai tugas yang sanggat penting yang sudah ditentukan dalam Peraturan Walikota Semarang Nomor 14A tentang Peraturan Internal Rumah Sakit (Hospital By Law) di RSUD KRMT Wongsonegoro Semarang untuk menjamin masyarat Semarang dan sekitarnya mendapatkan pelayan yang mudah dan cepat.

\section{Pelaksanaan Penyelenggaraan Rawat Jalan EKsekutif di RSUD KRMT Wongsonegoro Semarang}

Pelayanan rawat jalan eksekutif yang berada di RSUD KRMT Wongsonegoro Semarang sudah melayani pasien umum dan BPJS Non-PBI, dimana dalam pemberian pelayanan pasien BPJS Non PBI dilaksanakan pada sore hari dan pasien umum pada pagi hari. Sedangkan untuk biaya yang harus dikeluarkan oleh pasien BPJS Non-PBI masih tidak ada, hal ini terjadi karena rawat jalan 
eksekutif yang berada di RSUD KRMT Wongsonegoro belum mendapatkan MOU(Memorandum Of Understanding) dari BPJS, selain belum adanya MOU dengan BPJS rawat jalan eksekutif yang berada di RSUD KRMT Wongsonegoro Semarang juga belum mampu menjadwalkan semua dokter spesialis di rawat jalan eksekutif hal ini terjadi karena masih ada beberapa dokter spesialis yang jumlahnya kurang dari tiga, karena dalam Permenkes Nomor 11 Tahun 2016 tentang Penyelenggaraan Rawat Jalan Eksekutif minimal jumlah dokter spesialsubspesial berjumlah tiga orang. Rumah sakit juga sudah dapat menjadwalkan beberapa dokter di rawat jalan eksekutif tanpa harus menganggu rawat jalan reguler seperti spesialis penyakit dalam, sayaf, bedah.

Sedangkan untuk hal fasilitas yang terdapat dalam rawat jalan eksekutif di RSUD KRMT Wongsonegoro, sudah terdapat laboratorium, farmasi, radiologi, kasir, toilet, ruang tunggu dengan sofa dan AC.

Ketidak beradaan MOU dengan pihak BPJS secara tidak lansung berdampak pada pemberian pelayanan karena masih didapatkan ruangan yang belum dipergunakan dan pada sore hari dokter tidak terdapat di ruangan rawat jalan eksekutif.

\section{Perlindungan HAM Pasien BPJS Kesehatan dalam Pelayanan Rawat jalan Eksekutif di RSUD KRMT Wongsonegoro Semarang}

Peserta BPJS Kesehatan untuk mendapatkan pelayanan rawat jalan eksekutif sudah diatur dalam Permenkes Nomor 11 Tahun 2016 tentang Penyelenggaraan Rawat Jalan Eksekutif di Rumah Sakit Pasal 13 menjelaskan:

"Pelayanan rawat jalan eksekutif dapat diakses oleh peserta umum atau peserta JKN kecuali peserta penerima bantuan iuran dan peserta jaminan kesehatan yang didaftarkan oleh pemerintah daerah"

Peserta JKN dalam hal ini yang tidak dibayarkan oleh pemerintah dapat mengakses pelayanan rawat jalan eksekutif yang telah berada di rumah sakit dengan ketentuan yang sudah ditetapkan oleh masing-masing rumah sakit. Ketentuan peserta BPJS Kesehatan untuk dapat berobat ke rawat jalan eksekutif telah diatur dalam Permenkes Nomor 11 Tahun 2016 tentang Penyelenggaraan Rawat Jalan Eksekutif Pasal 13 ayat (2):

“Peserta JKN sebagaimana dimaksud pada ayat (1) harus memiliki surat rujukan dari fasilitas pelayanan kesehatan tingkat pertama, membuat peryataan mematuhi ketentuan sebagai pasien rawat jalan eksekutif, dan bersedia membayar selisih biaya pelayanan sesuai ketentuan perundang-undangan"

Dengan cara meminta dan membuat peryataan di fasilitas kesehatan tingkat pertama maka peserta BPJS Kesehatan Non-PBI dapat menikmati pelayanan rawat jalan eksekutif. Pasal 13 Permenkes Nomor 11 tahun 2016 tentang Penyelenggaraan Rawat jalan Eksekutif Di Rumah Sakit maka hak kesehatan 
akan lebih mudah dijangkau oleh masyarakat khususnya yang mempunyai jaminan BPJS Kesehatan Non-PBI.

Permenkes Nomor 71 Tahun 2013 tentang Pelayanan Kesehatan Pada Jaminan Kesehatan Nasional Pasal 21 ayat (1) yang berbunyi:

"Peserta yang menginginkan kelas perawatan yang lebih tinggi dari pada haknya, dapat meningkatkan haknya dengan mengikuti asuransi kesehatan tambahan, atau membayar sendiri selisih antara biaya yang dijaminkan oleh BPJS Kesehatan dengan biaya yang harus dibayar akibat peningkatan kelas perawatan."

Jika melihat rawat jalan eksekutif yang berada di rumah sakit maka, peserta jaminan sosial BPJS Kesehatan NON-PBI termasuk dalam peserta yang naik kelas perawatan, dimana dalam peserta yang naik kelas diwajibkan membayar selisih biaya yang harus dibayarkan. Jadi dengan adanya peraturan di atas maka peserta BPJS Kesehatan Non-PBI untuk dapat menikmati fasilitas kesehatang yang lebih tinggi diwajibkan membayar selisih biaya yang timbul.

\section{PENUTUP \\ KESIMPULAN}

Dari pembahasan di atas peneliti dapat menyimpulkan sebagai berikut:

1. Pengaturan Penyelenggaraan Rawat Jalan Eksekutif di RSUD KRMT Wongsonegoro Semarang

Berdasarkan dari pembahasan didapatkan bahwa rumah sakit dalam membuka rawat jalan eksekutif harus memenuhi beberapa peryaratan yang telah ditentukan oleh Permkenkes Nomor 11 Tahun 2016 tentang Penyelenggaraan Rawat Jalan Eksekutif di Rumah Sakit. Persyaratan yang pertama yaitu rumah sakit harus milik pemerintah pusat, pemerintah daerah dan masyarakat serta diselenggarakan pada rumah sakit tipe $A$, tipe $B$, dan tipe $C$ yang terdapat pada Pasal 2 Permenkes Nomor 11 Tahun 2016 tentang Penyelenggaraan Rawat Jalan Eksekutif di Rumah Sakit. RSUD KRMT Wongsonegoro Semarang dalam Peraturan Walikota Semarang Nomor 14A Tahun 2017 tentang Peraturan Internal Rumah sakit (Hospital By Law) Rumah Sakit Umum Daerah KRMT WOngsonegoro Semarang Pasal Pasal 1 poin 6 menjelaskan RSUD KRMT Wongsonegoro Semarang merupakan rumah sakit kelas $B$, poin 7 menjelaskan RSUD KRMT Wongsonegoro Semarang di miliki oleh Pemerintah Daerah.

RSUD KRMT Wongsonegoro dalam hal ini mengeluarkan Keputusan Direktur Nomor 290 Tahun 2017 tentang Pembukaan Pelayanan Rawat Jalan Eksekutif Paviliun Gatotkaca. Keputusan Direktur ini sangat penting karena dengan adanya keputusan ini maka RSUD KRMT Wongsonegoro telah resmi membuka rawat jalan eksekutif. 
Direktur RSUD KRMT Wongsonegoro dalam rawat jalan eksekutif juga menetapkan Keputusan Direktur Nomor 50 Tahun 2017 tentang Penetapan Tambahan Biaya Paket Pelayanan Rawat Jalan Eksekutif,

2. Pelaksanaan Penyelenggaraan Rawat jalan Eksekutif di RSUD KRMT Wongsonegoro Semarng

Dalam hal pelaksanaan rawat jalan eksekutif yang terdapat di RSUD KRMT Wongsonegoro Semarang, rumah sakit sudah mampu menjalankan beberapa ketentuan yang sudah ditetapkan oleh Permenkes Nomor 11 Tahun 2016 Pasal 3, dimana ketentuan tersebut berupa rumah sakit sudah mendirikan rawat jalan eksekutif tidak satu tempat dengan rawat jalan reguler, dalam rawat jalan eksekutif juga sudah terdapat pemeriksa penunjang. Tetapi dalam malasah tenaga kesehatan terutama dokter RSUD KRMT Wongsonegoro Semarang belum mampu menjadwalkan dokter spesialis-subspesialis sesuai dengan Pasal 12 Permenkes Nomor 11 Tahun 2016 tentang Penyelenggaraan Rawat Jalan Eksekutif

Pelayanan rawat jalan yang terdapat di RSUD KRMT Wongsonegoro Semarang belum mendapatkan MOU dengan pihak BPJS, yang mengakibatkan pelayanan rawat jalan bagi pasien BPJS Kesehatan Non-PBI tidak dikenakan tariff tambahan, selain itu ruangan yang berada di rawat jalan eksekutif RSUD KRMT Wongsonegoro juga banyak yang belum dipergunakan

3. Perlindungan HAM Pasien BPJS Kesehatan dalam Memperoleh Pelayanan Rawat Jalan Eksekutif di RSUD KRMT Wongsonegoro Semarang

Dalam hal perlindungan HAM terutama pasien BPJS Kesehatan Non-PBI anti diskriminasi dan kesetaraan, bahwa keberadaan rawat jalan bukan merupakan bentuk diskriminasi jika dilihat dari pandangan yuridis, karena dalam rawat jalan eksekutif terutama pasien BPJS Non-PBI dapat mengakses rawat jalan eksekutif yang sudah diataur dalam Permenkes Nomor 11 Tahun 2016 tentang Penyelenggaraan Rawat Jalan Eksekutif Pasal 13 dan diatur juga dalam Permenkes Nomor 71 Tahun 2016 tentang Pelayanan Kesehatan pada Jaminan Kesehatan Nasional Pasal 21 ayat (1), yang menjelaskan pasien BPJS dapat mengakses pelayanan yang lebih tinggi dari haknya dengan ketentuan peserta membayar biaya tambahan lagi. Permenkes Nomor 4 tentang Perubahan Kedua Atas Peraturan Menteri Kesehatan Nomor 52 Tahun 2016 Tentang Standar Tarif Pelayanan Kesehatan Dalam Menjalankan Program Jaminan Kesehatan, juga mengatur bahwa peserta BPJS dapat menikmati fasilitas yanglebih tinggi dari haknya dengan cara membayar selisih biaya.

Rawat jalan eksekutif akan terlihat diskriminasi jika dilihat dari padanga sosial, karena dalam satu rumah sakit terdapat dua pelayanan rawat jalan dimana yang satu rawat jalan umu yang dapat diakse oleh semua pasien baik pasien umum, BPJS PBI dan BPJS Non-PBI, sedangkan untuk rawat jalan eksekutif dapat diakses oleh pasien umu dan BPJS Non-PBI, yang manan peserta BPJS Kesehatan Non- 
PBI harus mentaati ketentun yang sudah ditentukan. Jika rawat jalan eksekutif dibandingkan dengan rawat jalan reguler maka akan terdapat perbedanperbedaan, seperti dalam pelayanan kesehatan dimana rawat jalan reguler dalam memeriksa pasien dibantu oleh coas, sedangkan rawat jalan reguler tidak.

\section{SARAN}

a. RSUD KRMT Wongsonegoro Semarang berusaha mendapatkan MOU dengan pihak BPJS yang nantinya dapat digunakan untuk melayani masyarakt dalam memenuhi hak atas kesehatan.

b. Dalam pencattan kunjungan pasien yang berobat ke rawat jalan eksekutif dapat dipisahkan antara jumlah kunjungan pasien BPJS dengan pasien umum.

c. Dalam memberikan pelayanan tidak ada pembagian jam pelayanan dimana sore untuk BPJS dan pagi untuk pasien umum, diharpkan agar baik pasien BPJS atau umum dapat mengakses pagi atau sore hari sehingga tidak terjadi diskrimiasi dalam pelayanan kesehatan.

\section{DAFTAR PUSTAKA}

Alifah, Ham Dalam Pelayanan Kesehatan, Internet, 06 Juli 2017, https://www.scribd.com/doc/291764776/HAM-dalam-Pelayanan-Kesehatan

Deklarasi Universal Hak-Hak Asasi Manusia, https://www.kontras.org/baru/Deklarasi\%20Universal\%20HAM.pdf diakes pada tanggal 2 juni 2017

Mahmud, Peter Marzuki. 2015, Penelitian Hukum. Jakarta: Kencana.

Mertokusumo, Sudikno. 2003, Mengenal Hukum Suatu Pengantar, Yogyakarta: Liberty.

Pengertian Perlindungan Hukum Menurut Para Ahli, http://tesishukum.com/pengertian-perlindungan-hukum-menurut-para-ahli/. Diakses pada tanggal 12 Maret 2018.

Rahma, Ham dalam Bidang Kesehatan, 01 Februhari 2017, Online, Internet, 03 juli 2017, https://btlprahma.blogspot.co.id/2017/02/makalah-ham-dalam-bidangkesehatan.htm

Riduwan. 2014. Metode dan Teknik Penyusunan Tesis. Bandung: Alfabeta.

Salahuddin Wahid, Kesehatan Sebagai Hak Asasi Manusia, http://makalahplus.blogspot.co.id/2013/08/kesehatan-sebagai-hak-asasimanusia.html diakses pada tanggal 03 mei 2017 jam 18.00. 
Undang-Undang Dasar 1945

Undang-Undang No. 39 Tahun 1999 tentang HAM

Undang-Undang No. 40 Tahun 2004 tentang Sistem Jaminan Sosial Nasional

Undang-Undang No. 44 Tahun 2009 tentang Rumah Sakit

Undang-Undang No. 39 Tahun 2009 tentang Kesehatan

Undang-Undang No. 24 Tahun 2011 tentang Badan Penyelengara Jaminan Sosial

Peraturan Presiden No. 111 Tahun 2013 tentang Perubahan Atas Peraturan Presiden No. 12 Tahun 2013 tentang Jaminan Kesehatan.

Peraturan Menteri Kesehatan No. 11 Tahun 2016 tentang Penyelenggaraan Rawat Jalan Eksekutif

Permenkes Nomor 4 Tahun 2017 tentang Perubahan Kedua tentang Peraturan Menteri Kesehatan Nomor 52 Tahun 2016 tentang Standar Tarif Pelayanan Kesehatan dalam Penyelenggaraan Program Jaminan Kesehatan 